\title{
Probabilistic Evaluation of Tibetan Plateau Mesoscale Vortex on 18 July 2013
}

\author{
Haiwen Liu (D), Kaijun Wu (D), Mengxing Du (D), and Ning Fu (i) \\ Department of Aviation Meteorology, Civil Aviation University of China, Tianjin 300300, China \\ Correspondence should be addressed to Mengxing Du; mxdu@cauc.edu.cn
}

Received 10 December 2018; Revised 7 March 2019; Accepted 22 April 2019; Published 13 May 2019

Academic Editor: Helena A. Flocas

Copyright ( $\odot 2019$ Haiwen Liu et al. This is an open access article distributed under the Creative Commons Attribution License, which permits unrestricted use, distribution, and reproduction in any medium, provided the original work is properly cited.

Tibetan Plateau (TP) mesoscale vortex (TPMV) was regarded as one of the most important rain bearing systems in China. Previous studies focused on the mechanisms of the TPMV in the viewpoint of deterministic forecast; however, few studies investigate the predictability of the TPMV using the Observing System Research and Predictability Experiment (THORPEX) Interactive Grand Global Ensemble (TIGGE) from the European Center for Medium Range Weather Forecasts (ECWMF). This paper investigates the location and the intensity of the larger-scale synoptic systems that influenced the development of the TPMV and its associated heavy rainfall by correlation and composite analysis. The case study on 18 July 2013 shows that stronger Balkhash Lake ridge, weaker Baikal Lake trough, and weaker western Pacific subtropical high (WPSH) are favorable to formation of TPMV over the Sichuan basin (SCB); otherwise, weaker Balkhash Lake ridge, stronger Baikal Lake trough, and stronger WPSH result in formation of TPMV to west of the SCB slightly. After the initial time, forecast for next $48 \mathrm{~h}$ of the geopotential height over the SCB can be viewed as a precursor of the subsequent time-averaged 90-108 h forecast of TPMV. TPMV had critical contributions to the heavy rainfall over the SCB on 18 July 2013.

\section{Introduction}

Tibetan Plateau (TP) mesoscale vortex (TPMV), with a typical horizontal scale of several hundred kilometers, frequently occurs over the TP in boreal summer [1-4]. As one of the major rain bearing systems [5-7], TPMV can give rise to the extreme rainfall events in East Asia, including China, Korea, and Japan $[2,3]$. Based on the locations and heights in the troposphere, generally, the subsynoptic or mesoscale convective systems are named as TPMV or southwest vortex (SWV), respectively. In China, TPMV is even regarded to be the second heavy precipitation causing system after the tropical cyclones [8]. For example, the severe flood in 1998 over the Yangtze River basin was considered to be triggered by the eastward-propagating TPMV [9-11].

Partly due to the scarcity of meteorological observations over the TP and its adjacent area, our knowledge concerning the formation of TPMV is less deep than that of the tropical cyclones in China. To compensate for the limitation in capturing the TPMV and the SWV by a conventional observational network, two major Tibetan Plateau scientific field experiments were conducted in 1979 and 1998 [12], respectively. Over the past decades, a number of hypotheses have been made to explain the genesis, movement, and structure of the TPMV and SWV from thermodynamical and dynamical environments over the plateau [13, 14]. Takahashi [15] suggested that the lower level cold air mass contributed to the formation of TPMV. Ye and Gao [7] pointed out that the shallow cyclonic vortices developed and moved out from the TP when the favorable conditions occurred at a higher level. The large-scale circulations and the TP topographic effects and the release of convective latent heat were contributed to the development of TPMV during the rainy season (e.g., Wang [3]; Shi et al. [9]; Dell'Osso and Chen [16]; Gao [17]; Shen et al. [18]; Sugimoto and Ueno [19]; Zhou et al. [20]). Recently, the climatology of TPMVs and SWVs were studied by objective tracking approaches $[21,22]$; these results provided the geographical distribution of TPMVs and SWVs and further enhanced the understanding of the TPMVs and SWVs. 
As ensembles of numerical weather prediction models are more and more used in the daily weather forecasting, some investigators used ensemble forecasts to analyze the dynamics of the weather system. For example, Schumacher [23] used ensemble forecasts to determine the synoptic and mesoscale factors on the development of a vortex and its associated heavy rainfall over the southern plains of the United States during 25 to 30 June 2007. Qian et al. [24] examined the uncertainties in the track forecast of the European Center for Medium Range Weather Forecasts (ECMWF) operational ensemble about super typhoon Megi. Torn [25] also applied the techniques to investigate the dynamics of the tropical cyclones (TCs). Hawblitzel et al. [26] as well as Sippel and Zhang [27, 28] explored the genesis of mesoscale convective vortices (MCVs) and TCs using similar techniques. Recently, Li et al. [29] examined the parameters associated with the SWV movement using an ensemble prediction system to diagnose the dynamical and thermodynamical characteristics about the eastward movement and growth of SWV.

While the previous studies mostly focused on the genesis, movement, and structure of the TPMV in viewpoint of determinable prediction, few studies [30] have investigated the TPMV using the ECWMF Ensemble Prediction product [31], e.g., using the ECMWF ensemble data and NCEP reanalysis data, Wang et al. [30] found that the plateau vortex moving eastward and coupling with SWV is the key factor to the persistent heavy rainfall over the SCB on 30 June 2013. In this study, we attempt to investigate the weather systems that favor for or not favor for the development of TPMV and the associated heavy rainfall, using the Observing System Research and Predictability Experiment (THORPEX) Interactive Grand Global Ensemble (TIGGE; Bougeault et al. [32]). The following questions will be answered: why do some ensemble members produce a TPMVassociated heavy rainfall, while others do not? What are the precursors to the development or nondevelopment of TPMV in the ensemble? How long is leading time to forecast the TPMV and the associated heavy rainfall? In addition to answering these questions, another important purpose of this study is to evaluate the utility of the TIGGE in the one of the most complicated topography areas in the world.

The remainder of this article is organized as follows. Section 2 briefly introduces the datasets and methodology. In Section 3, the episode selection and the synoptic overview are presented. Section 4 presents the results, including differences in the strength of TPMV of the ensemble members, lager-scale factors influencing the development of the TPMV, and detailed processes that are favorable or detrimental to the development of TPMV and its associated heavy rainfall over the Sichuan basin (SCB). Finally, the conclusions and discussion are provided in Section 5.

\section{Data and Analysis Methods}

Six hourly ERA-Interim reanalysis data with a horizontal $0.75^{\circ} \times 0.75^{\circ}$ resolution and 37 pressure levels from 1000 to $1 \mathrm{hPa}$ [33] are used for synoptic analyses. To determine the synoptic mesoscale factors that lead to the development of the TPMV and its associated heavy rainfall, the ensemble forecast data used here are TIGGE from the ECWMF Ensemble Prediction System [32].

The ensemble includes a control run and 50 members, and the initial perturbation method of members is adopted by singular vectors in pairs and by stochastic physics. A 51member ensemble is coming from the spectral truncation of T399 with 62 vertical levels and through 240 forecast hours from the TIGGE archive. The horizontal fields were bilinearly interpolated from global Gaussian grid to $0.75^{\circ} \times 0.75^{\circ}$ to coincide with the ERA-Interim reanalysis data. The daily gauged rainfall data (1800-1200 UTC) are provided by Meteorological Information Center of China Meteorological Administration (CMA).

To elucidate the favorable or detrimental processes to the development of TPMV and heavy rainfall on 18 July 2013 (1800 UTC 17 July-1200 UTC 18 July), the value of areaaveraged $500 \mathrm{hPa}$ geopotential height $(\mathrm{GPH})$ and original gauged rainfall over the $\operatorname{SCB}\left(26^{\circ} \mathrm{N}-34.25^{\circ} \mathrm{N}, 97.25^{\circ} \mathrm{E}-\right.$ $108.5^{\circ} \mathrm{E}$ ) of 18 July (4 times average) are defined as the TPMV index (TPMVI) and $\mathrm{P}$, respectively.

Following the method used by Sippel and Zhang [27], linear correlations between the TPMVI and $500 \mathrm{hPa}$ GPH within the entire ensemble members are calculated at each grid point and different forecast time. Correlations are used here for simplicity to illustrate studying physical relationships between several atmospheric variables and TPMV within the ensemble, although the linear correlations do not necessarily interpret causality (Schumacher [23]; Sippel and Zhang [27]; Hakim and Torn [34]). To physically interpret the difference between the stronger and weaker members for the predictability of TPMV, the composite (averaged) method is also used in this paper.

\section{Case Overview}

Located in the east of TP, the SCB (red dashed box in Figure 1) experienced consecutive heavy rainfall events (Figure 2) in July 2013. The continuous precipitation caused the deadly and destructive flooding for Sichuan Province [35]. The total economic loss brought by the flood was viewed as the most seriously events since the heavy rainfall occurred over the SCB in 11-15 July 1981 [35]. As the heaviest rainfall occurred on 18 July 2013 (Figure 2), this episode is selected for study in this paper.

The heavy rainfall is associated with the favorable synoptic situations [36]. At $500 \mathrm{hPa}$ weather charts on 17 July 2013 in Figure 3(a), two low pressure centers were observed in mid-high latitudes. One was located in the Ural Mountains, and the other was in Baikal Lake; meanwhile, another weak ridge was located over the Sea of Okhotsk. Kuo et al. [37] had proposed that the unusually strong Baikal Lake trough in summer provided a favorable environment for the organization of a mesoscale vortex over the SCB. In middle latitudes, the flow between the $40^{\circ} \mathrm{N}-50^{\circ} \mathrm{N}$ was zonally distributed, although the short wave troughs over the Balkhash Lake and the southwest of the Baikal Lake were still observed. Meanwhile, a northeast-southwest trough was located in the north of the SCB. Notably, western Pacific 


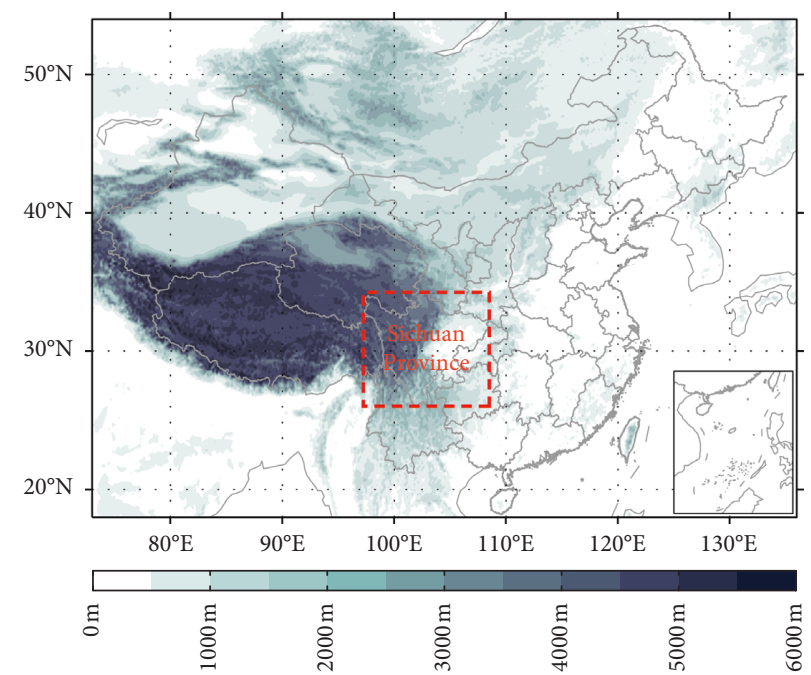

Figure 1: Map of terrain elevations (shaded every $1000 \mathrm{~m}$ ) in eastern Eurasia and the region of Sichuan Province in the red dashed box.

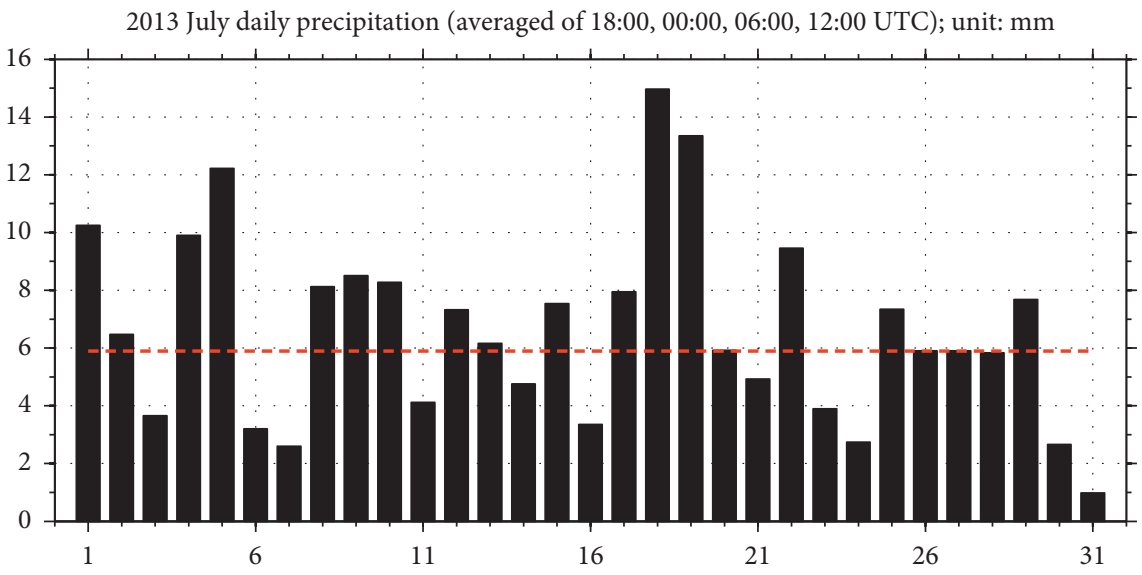

FIgURE 2: Time series of daily precipitation (unit: $\mathrm{mm}$ ) averaged over Sichuan Province from 1 to 31 July in 2013 using the gauge-based precipitation data. The red line shows the climate mean (1981-2010) of July precipitation value (5.89 mm) over the Sichuan Province.

subtropical high (WPSH) meridionally oriented along a northeast-southwest axis was over the west of the Pacific Ocean. After 24 hours in Figure 3(b), on 18 July, the trough over Ural Mountains was steady and varied a little, and the Baikal Lake trough moved northward and became more meridional. And at this time, a closed midlevel circulation (TPMV) had developed, and the TPMV brought about heavy rainfall exceeding $100 \mathrm{~mm}$ during the period from 1200 UTC 17 July to 1200 UTC 18 July.

\section{Results}

4.1. Composites Analysis of the Stronger and Weaker Members. ECWMF Ensemble Prediction System [29] forecasts were initialized at 0000 UTC 14 July 2013. Figure 4 shows the reason why we chose this initialization time. As shown in Figure 4, the initialization time at 0000 UTC 14 July not only has enough lead time for studying the forecast signal but also has more accurate forecast signals of the TPMV than 0000 UTC 15 July and 0000 UTC 16 July. The TPMV is one of the important weather systems producing the extreme rainfall events in SCB [30]. To measure the differences among the ensemble results about TPMV, we divide the 50 members into stronger (weaker) groups with 6 minimum (maximum) TPMVI values. So the "stronger" group consists of 6 members, and the "weaker" group consists of 6 members.

The composites of the $500 \mathrm{hPa} \mathrm{GPH}$ fields and its associated wind fields on 18 July for these two groups are shown in Figure 5. A common feature of both stronger group and weaker group is the quasizonal alignment of low GPH centers between $50^{\circ} \mathrm{N}$ and $60^{\circ} \mathrm{N}$. Two troughs are located over the southeast of the Ural Mountains $\left(50^{\circ} \mathrm{N}-60^{\circ} \mathrm{N}\right.$, $\left.60^{\circ} \mathrm{E}-80^{\circ} \mathrm{E}\right)$ and the Baikal Lake $\left(50^{\circ} \mathrm{N}-60^{\circ} \mathrm{N}, 100^{\circ} \mathrm{E}-120^{\circ} \mathrm{E}\right.$, Baikal Lake trough hereafter), respectively. The striking difference is that the Baikal Lake trough in stronger group is weaker and tilts less than that in weaker group while the 5820 contours are much closer to the SCB in stronger group than that in weaker group. In middle latitudes $\left(40^{\circ} \mathrm{N}-50^{\circ} \mathrm{N}\right.$, $100^{\circ} \mathrm{E}-120^{\circ} \mathrm{E}$ ), the flow is essentially zonal over Eurasia. The southern end of the trough over the south of Baikal Lake 


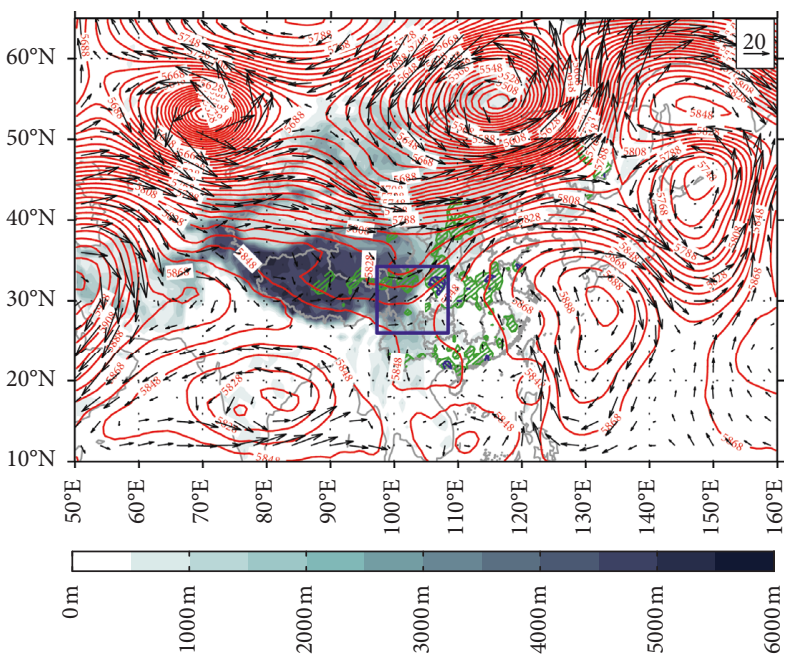

(a)

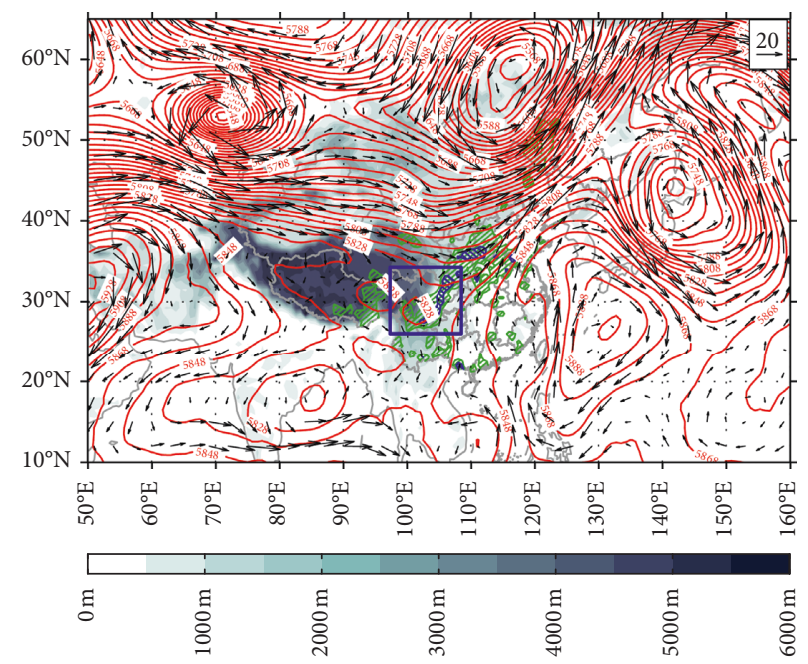

(b)

FIgURE 3: Averaged $500 \mathrm{hPa}$ geopotential heights (GPHs) (red contours; unit: gpm) and wind (black vectors; unit: m/s) from ERA-Interim reanalysis data and gauge-based precipitation data (green contours for $10 \mathrm{~mm}$ and blue contours for $50 \mathrm{~mm}$ ) for $24 \mathrm{~h}$ period: (a) $1200 \mathrm{UTC}$ 16 July-1200 UTC 17 July; (b) 1200 UTC 17 July-1200 UTC 18 July. The blue rectangle indicates the Sichuan Province area where 500 hPa GPHs are averaged. The shaded areas show the terrain elevations (shaded every $1000 \mathrm{~m}$ ) in eastern Eurasia.

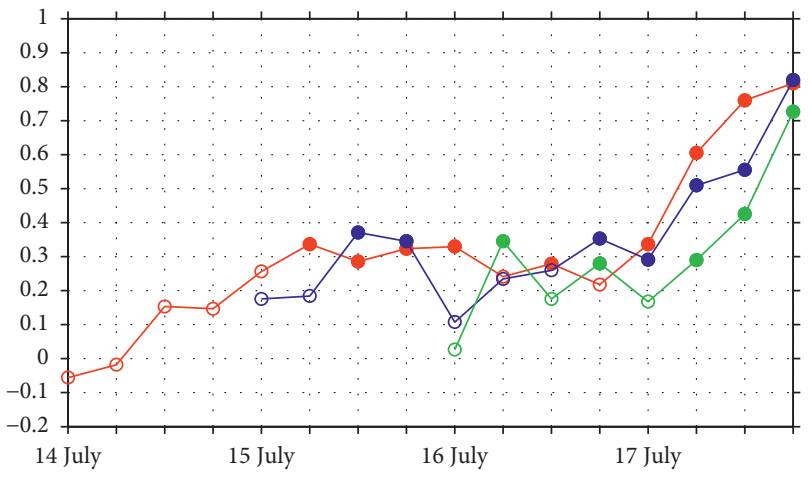

Figure 4: Time series ( $6 \mathrm{~h}$ interval) of correlations between the averaged $500 \mathrm{hPa}$ GPHs over the SCB in forecast for next 0 90 hours after the initial time 0000 UTC 14 July and TPMVI (red line), for next $0-66$ hours after the initial time 0000 UTC 15 July and TPMVI (blue line), and for next $0-42$ hours after the initial time 0000 UTC 16 July and TPMVI (green line). The solid dots show the correlations reaching $95 \%$ confidence level.

moves to the north of the SCB, and the flow pattern forms the "North trough-South vortex," which is a typical flow pattern for heavy rain over the SCB [38]. Baikal Lake trough is slightly further south and deeper in the stronger group than that in the weaker group. Note that the TPMV is just located over the SCB in Figure 5(a) and slightly further east in the stronger group than that in the weaker group in Figure 5(b). WPSH is more meridional and its western boundary extends further east in the stronger group than that in the weaker group.

Figure 5(c) further shows the differences between two groups. The distinction is that a significant "- +-" pattern of GPH anomalies dominates over the Eurasian continent in the meridional direction. The negative values cover the northwest of the Sea of Okhotsk $\left(55^{\circ} \mathrm{N}-65^{\circ} \mathrm{N}, 82^{\circ} \mathrm{E}-140^{\circ} \mathrm{E}\right)$ and the low latitudes from the east of the TP to the west Pacific Ocean, with positive values over the Eurasian continent. According to an objective criterion of the trough and ridge, the negative GPH differences imply stronger troughs in the stronger group and the positive GPH differences imply stronger ridges in the stronger group. These features imply that Baikal Lake trough and the WPSH are weaker in the stronger group than that in the weaker group; meanwhile, Balkhash Lake ridge $\left(40^{\circ} \mathrm{N}-50^{\circ} \mathrm{N}, 82^{\circ} \mathrm{E}-100^{\circ} \mathrm{E}\right)$ and TPMV in the stronger group are stronger than that in the weaker group. These features are consistent with the discussions above.

4.2. Lager-Scale Factors Influencing the Development of the $T P M V$. To elucidate the favorable or detrimental processes to the development of the TPMV, composites of the "stronger" group and the "weaker" group and linear correlations between $500 \mathrm{hPa}$ GPHs and TPMVI within the entire ensemble members are calculated at each grid point and different forecast time. Forecasted atmospheric fields leading up to the chosen time can be regarded as precursors to the development of the TPMV over the SCB. Due to the movement of the midhigh latitude synoptic systems over time, the possible precursors of synoptic systems are masked by asterisk in the midhigh latitudes. Because of the difficulty to indicate the jump of the WPSH at $500 \mathrm{hPa}$, the area in the dashed blue box where the correlations coefficient is roughly beyond the $95 \%$ confidence level near WPSH depicts the influence of the WPSH. To measure the WPSH, the regions used to be calculated GPH in the dashed blue box from Figure 6(a) to 6(i) were $\left(22.5^{\circ} \mathrm{N}-31.5^{\circ} \mathrm{N}, \quad 113.5^{\circ} \mathrm{E}-125^{\circ} \mathrm{E}\right), \quad\left(22.5^{\circ} \mathrm{N}-32.5^{\circ} \mathrm{N}, \quad 113.5^{\circ} \mathrm{E}-\right.$ $\left.123.5^{\circ} \mathrm{E}\right),\left(24.5^{\circ} \mathrm{N}-32.5^{\circ} \mathrm{N}, 112.5^{\circ} \mathrm{E}-120.5^{\circ} \mathrm{E}\right),\left(24.5^{\circ} \mathrm{N}-33^{\circ} \mathrm{N}\right.$, $\left.112.5^{\circ} \mathrm{E}-123.5^{\circ} \mathrm{E}\right),\left(25.5^{\circ} \mathrm{N}-32^{\circ} \mathrm{N}, 110.5^{\circ} \mathrm{E}-124.5^{\circ} \mathrm{E}\right),\left(25.5^{\circ} \mathrm{N}-\right.$ 


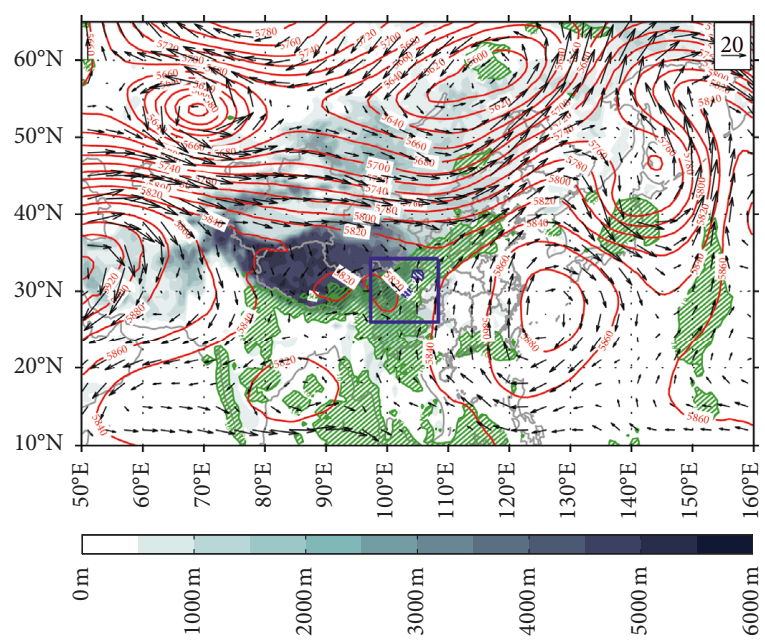

(a)

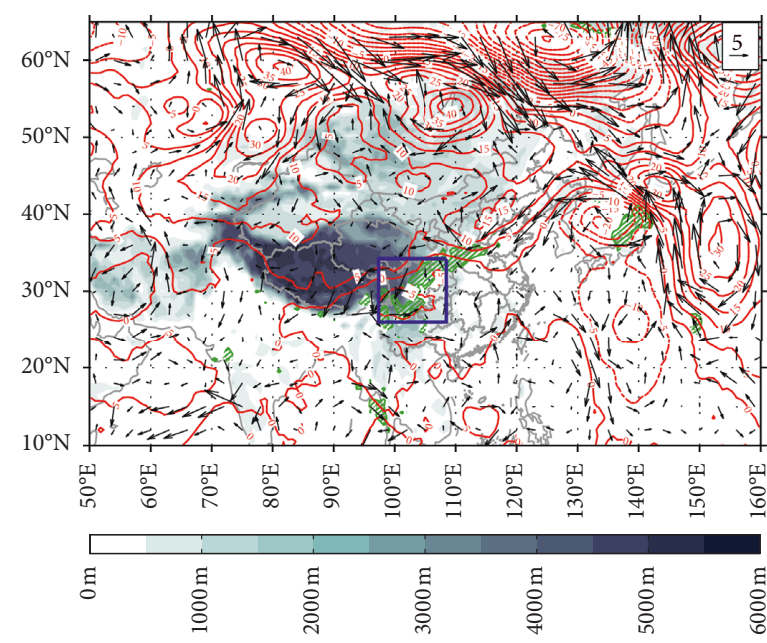

(b)

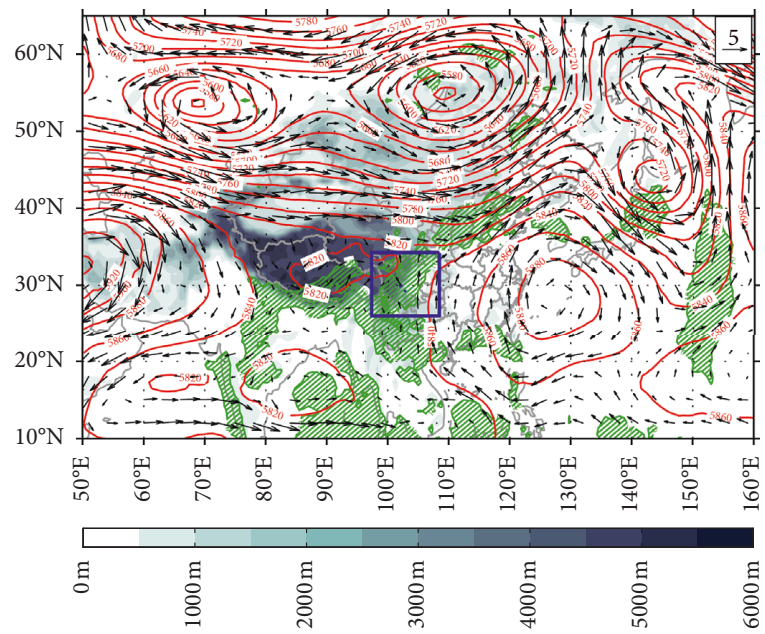

(c)

FIgURE 5: The $500 \mathrm{hPa}$ GPHs (red contours; unit: gpm) and wind (black vectors; unit: $\mathrm{m} / \mathrm{s}$ ) from ERA-Interim reanalysis data and gaugebased precipitation data (green contours for $10 \mathrm{~mm}$ and blue contours for $50 \mathrm{~mm}$ ) in forecast for next 90-108 h (4-time average, 1800 UTC 17 July-1200 UTC 18 July) after the initial time of 0000 UTC 14 July 2013. (a) Composite of six stronger members with the lowest values of TPMVI. (b) Composite of six members with the highest values of TPMVI. (c) Difference by six stronger members minus six weaker members. The blue rectangle indicates the Sichuan Province. The shaded areas show the terrain elevations (shaded every $1000 \mathrm{~m}$ ) in eastern Eurasia.

$\left.32.5^{\circ} \mathrm{N}, 110.5^{\circ} \mathrm{E}-119.5^{\circ} \mathrm{E}\right),\left(26.5^{\circ} \mathrm{N}-34.5^{\circ} \mathrm{N}, 110.5^{\circ} \mathrm{E}-119.5^{\circ} \mathrm{E}\right)$, and $\left(24.5^{\circ} \mathrm{N}-33.5^{\circ} \mathrm{N}, 108.5^{\circ} \mathrm{E}-117.5^{\circ} \mathrm{E}\right)$, respectively. The TPMV is shown in the black box over the SCB in Figure 6. As shown in Figure 6, area with continuous correlations is obvious from the beginning of the forecast for next $48 \mathrm{~h}$. The negative correlations are evident over Ural Mountains at the forecast for next $48 \mathrm{~h}$ in Figure 6(e) and then moved to the southwest of the Baikal Lake in Figure 6(f). This indicates that there is a stronger TPMV when there is a weaker Baikal Lake trough. The shallower Baikal Lake trough also suggests that weaker cold air flow coming from the mid-high latitudes benefits the formation of the TPMV. This feature has some differences from the proposal by Kuo et al. [37], which stated that colder air flows would benefit the formation and development of the TPMV. The difference of the east winds located in the north of the SCB in Figure 7 and the weaker
Baikal Lake trough in the stronger members (Figures 7(f)7(i)) further support the viewpoint mentioned above.

Besides the feature of a negative correlation from the Ural Mountains to the southwest of the Baikal Lake mentioned above, another positive correlation center located in the south of the Balkhash Lake $\left(38^{\circ} \mathrm{N}-42^{\circ} \mathrm{N}, 75^{\circ} \mathrm{E}-85^{\circ} \mathrm{E}\right)$ is also observed in Figure 6. This positive correlation center over Balkhash Lake area is apparent in the forecast for next $60 \mathrm{~h}$ (Figure 6(f)). As the time progressed, the positive correlation area mentioned above becomes wider in Figure $6(\mathrm{~g})$, and finally it merges with another positive center over the northwest of the SCB $\left(22^{\circ} \mathrm{N}-50^{\circ} \mathrm{N}, 75^{\circ} \mathrm{E}-\right.$ $100^{\circ} \mathrm{E}$ ) in the forecast for next $84 \mathrm{~h}$ (Figure $6(\mathrm{~h})$ ). Corresponding to the positive center over the northwest of the SCB in Figure 6(f), a stronger ridge in the south of the Balkhash Lake is observed in the stronger members with 


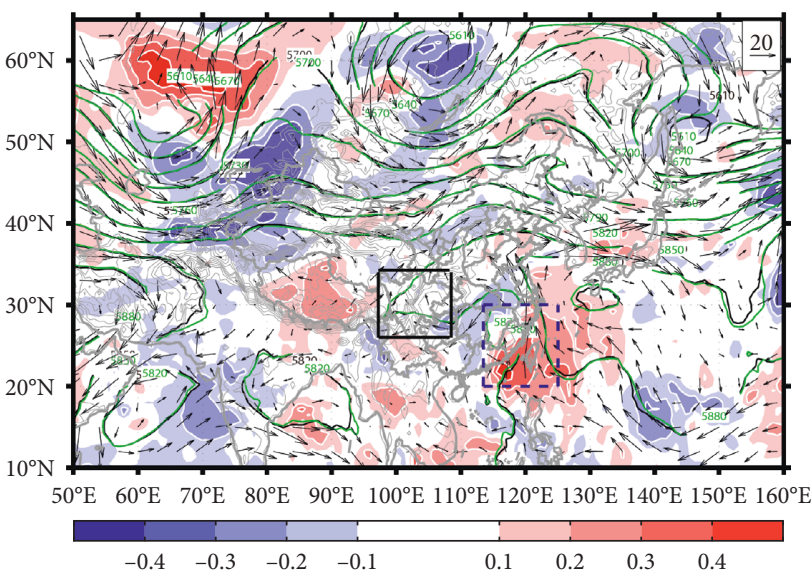

(a)

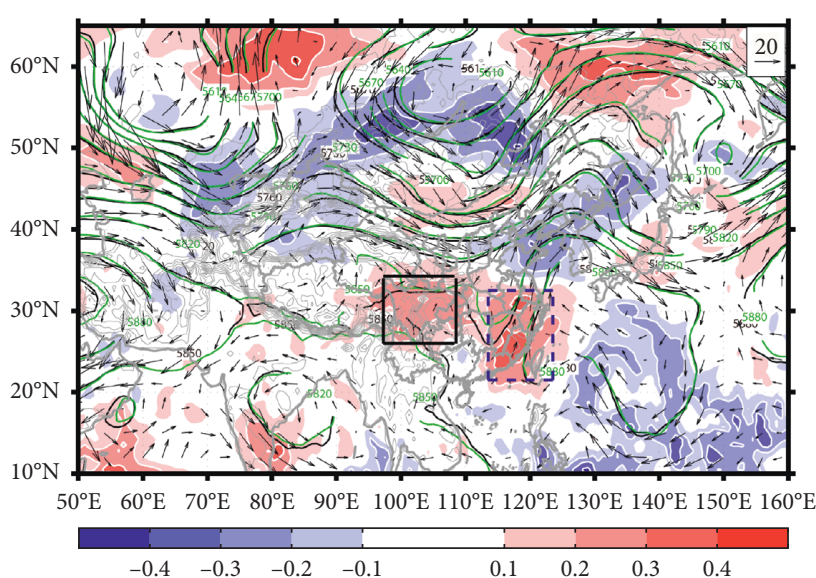

(c)

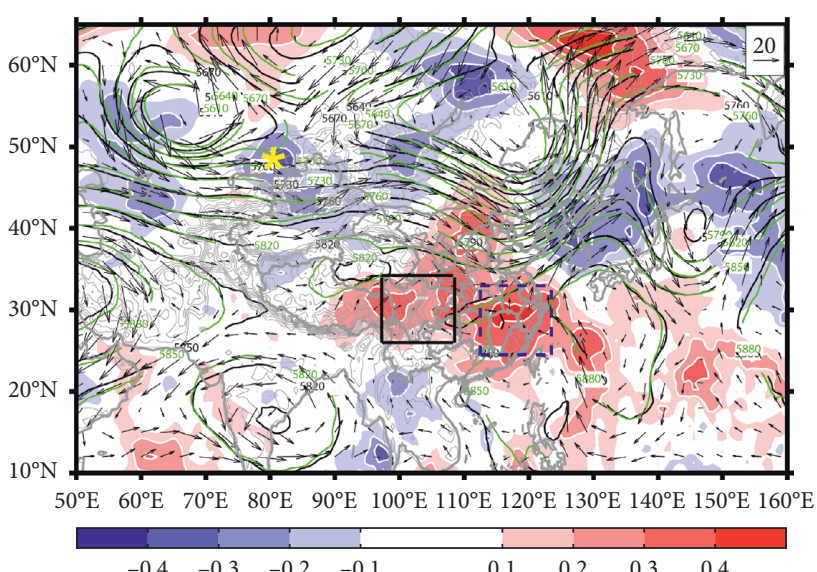

(e)

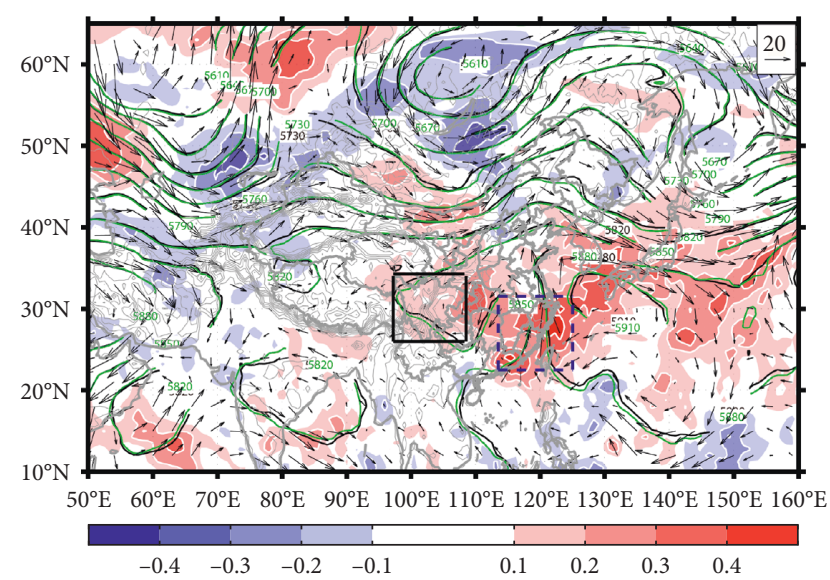

(b)

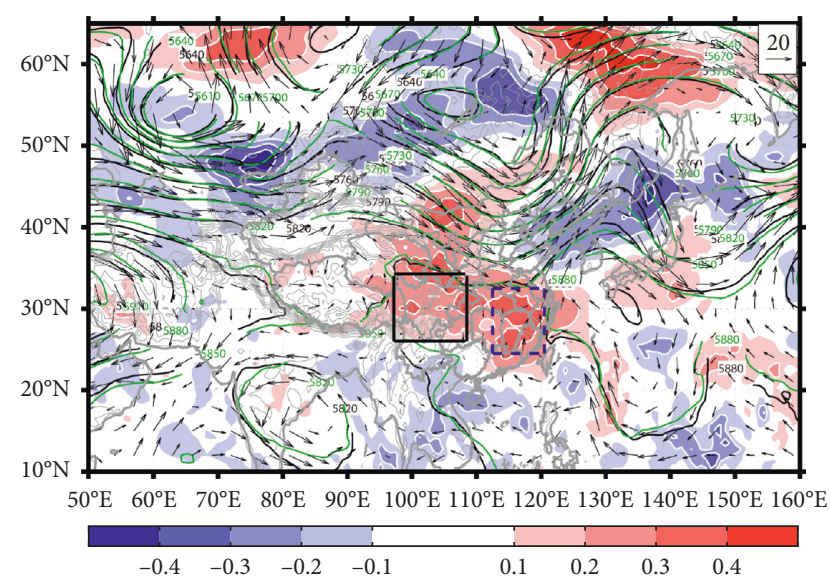

(d)

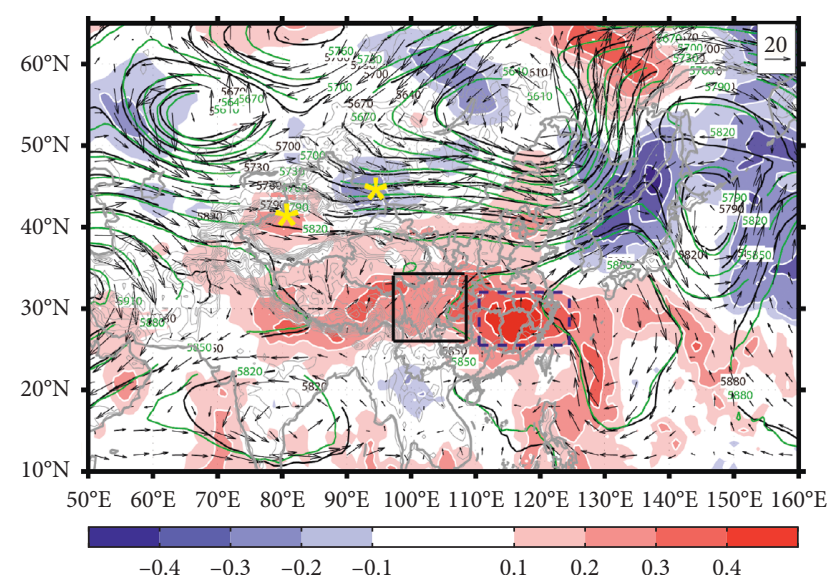

(f)

Figure 6: Continued. 


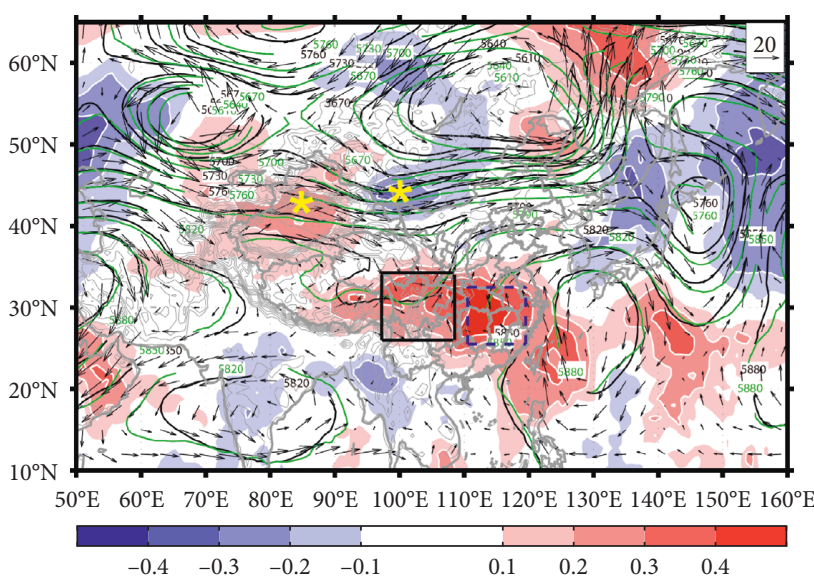

(g)

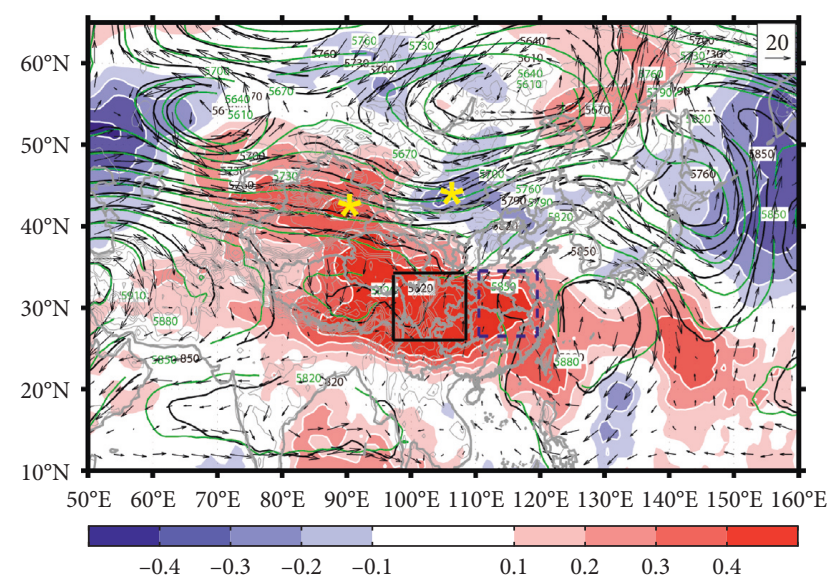

(h)

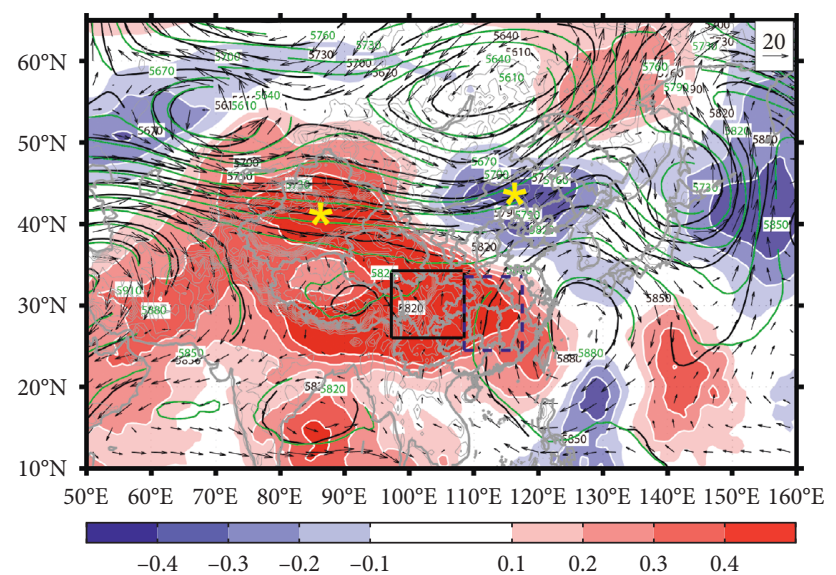

(i)

FIGURE 6: Correlation (color shading) between TPMVI and $500 \mathrm{hPa} \mathrm{GPH}$ in the 50 -member forecast for next 0 to $84 \mathrm{~h}$ (12 h interval) in (a-h) and for next 90-108 h (4-time average, 1800 UTC 17 July-1200 UTC 18 July) in (i) initialized at 0000 UTC 14 July 2013 . The black contours and black vectors are the ensemble-mean of the $500 \mathrm{hPa}$ GPHs (unit: gpm) and winds (unit: $\mathrm{m} / \mathrm{s}$ ) of 6 stronger members, and the green contour is the ensemble-mean of the $500 \mathrm{hPa}$ GPHs (unit: gpm) of 6 weaker members. The asterisk shows the significant location of the correlation according to the synoptic systems coherent rules. The blue boxes in Figures 6(a)-6(i) show the area with correlations coefficient roughly beyond the $95 \%$ confidence level near WPSH and the black boxes indicate the TPMV over the SCB, respectively.

respect to the weak members, where positive difference of GPH is also shown in Figure 7(f). This suggests that the stronger Balkhash Lake ridge in the south of the Balkhash Lake favors for the formation of the TPMV over the SCB. Otherwise, the weaker Balkhash Lake ridge in the south of the Balkhash Lake results in formation of TPMV to west of the SCB slightly. Figure 7 also demonstrates that the westerly air flow is weaker in the stronger members than that in the weaker members in the north of the SCB. Combining with the shallower Baikal Lake trough in the Figure 6(i), we can deduce that a weaker cold flow coming from the mid-high latitudes favors the formation and the development of the TPMV.

Meanwhile, in the low-mid latitudes, the previous GPHs over the SCB and WPSH are also important for the formation of TPMV. As shown in Figure 6, a persistent and steady positive correlation center between the TPMVI and the $500 \mathrm{hPa} \mathrm{GPH}$ near the WPSH is observed from the initial time. To further illustrate the relationship between the
WPSH and TPMV, Figure 8 shows the time series of the correlations between the WPSH and TPMVI. The areaaveraged GPHs at $500 \mathrm{hPa}$ in the dashed blue box from Figures 6(a) to 6(i) represent WPSH. The significant positive correlation values increase since the forecast for next $24 \mathrm{~h}$ (valid 0000 UTC 15 July), and most correlation values exceed the horizontal line of the $95 \%$ confidence level with $R=0.36$ after the forecast for next $24 \mathrm{~h}$ in Figure 8. This suggests that there is a stronger TPMV when WPSH is weaker. Figure 6 also indicates that TPMV is obstructed by the stronger WPSH in the weaker members, and TPMV is easily located over the TP and slightly further west than that in the stronger members. It is obvious that the TPMV located even slightly further west is not favorable to the heavy rainfall over the SCB.

Figure 9 shows that $500 \mathrm{hPa}$ GPH in the forecast for the next $48 \mathrm{~h}$ over the SCB plays an important role on the TPMV on 18 July 2013. The correlation coefficient between the averaged GPHs and TPMVI is 0.33, which passed the $95 \%$ 


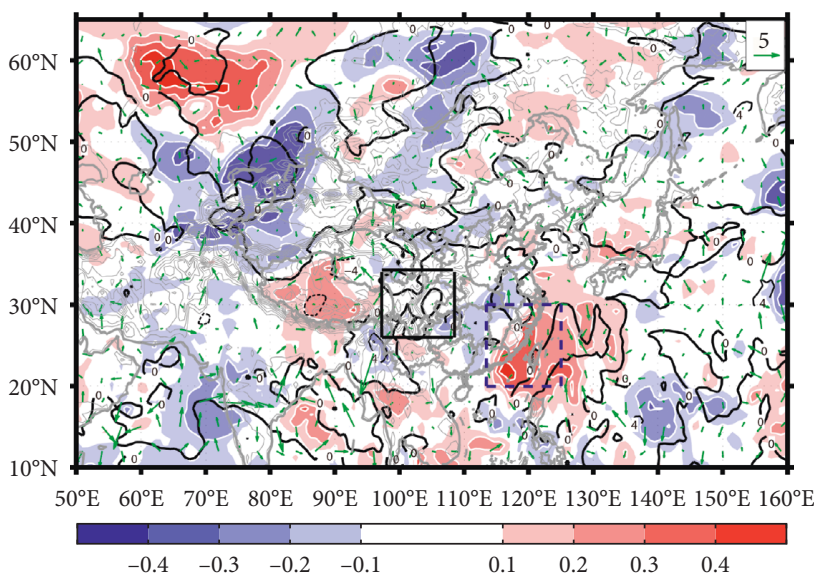

(a)
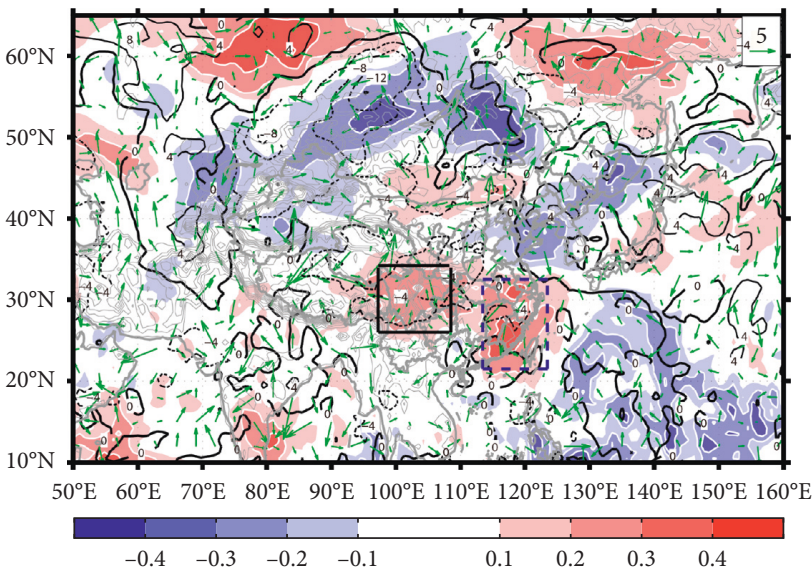

(c)

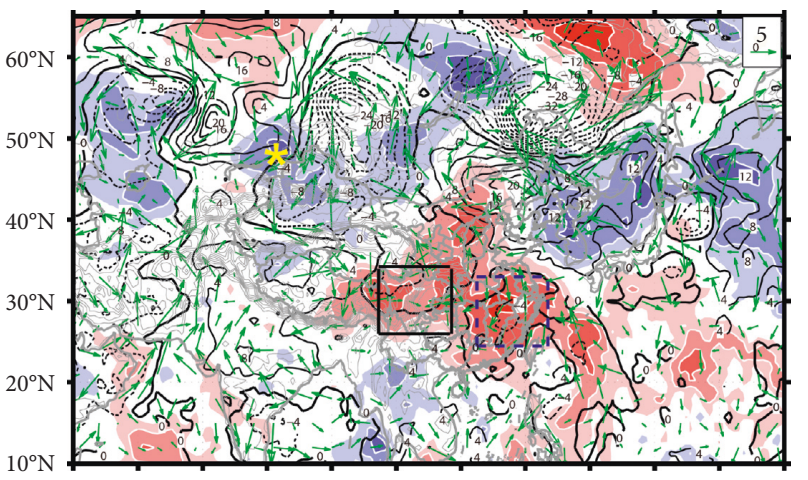

$50^{\circ} \mathrm{E} \quad 60^{\circ} \mathrm{E} \quad 70^{\circ} \mathrm{E} \quad 80^{\circ} \mathrm{E} \quad 90^{\circ} \mathrm{E} \quad 100^{\circ} \mathrm{E} 110^{\circ} \mathrm{E} 120^{\circ} \mathrm{E} 130^{\circ} \mathrm{E} 140^{\circ} \mathrm{E} 150^{\circ} \mathrm{E} 160^{\circ} \mathrm{E}$

$\begin{array}{lllllllll}-0.4 & -0.3 & -0.2 & -0.1 & 0.1 & 0.2 & 0.3 & 0.4\end{array}$

(e)

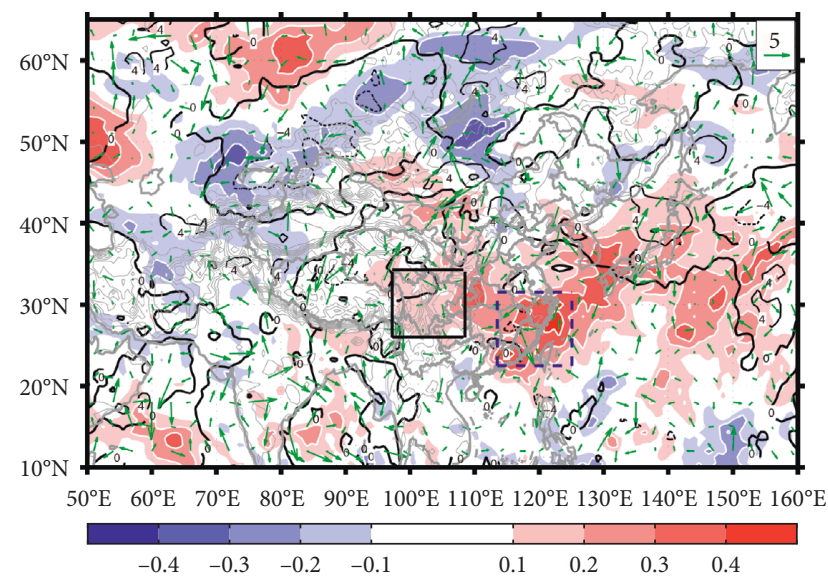

(b)

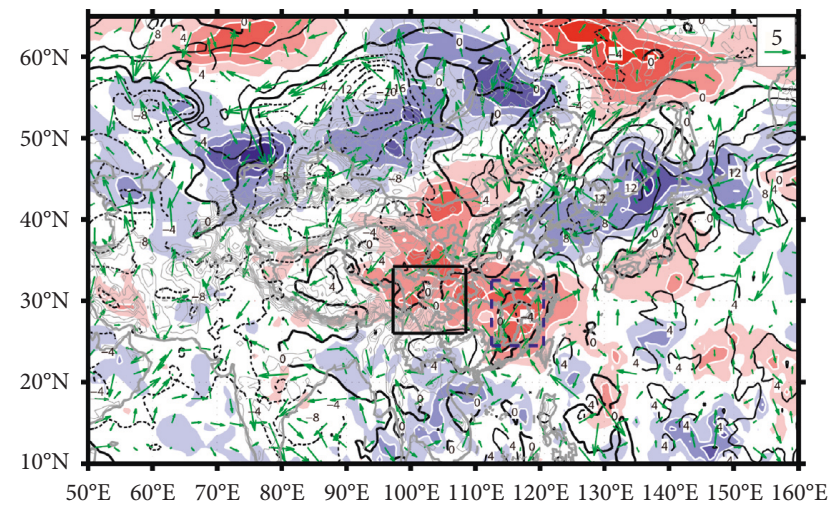

$\begin{array}{llllllll}-0.4 & -0.3 & -0.2 & -0.1 & 0.1 & 0.2 & 0.3 & 0.4\end{array}$

(d)

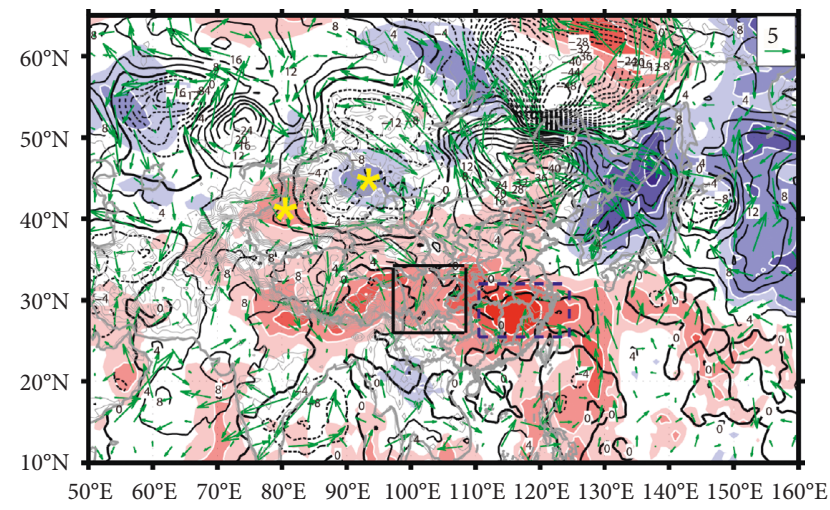

$\begin{array}{llllllll}-0.4 & -0.3 & -0.2 & -0.1 & 0.1 & 0.2 & 0.3 & 0.4\end{array}$

(f)

Figure 7: Continued. 


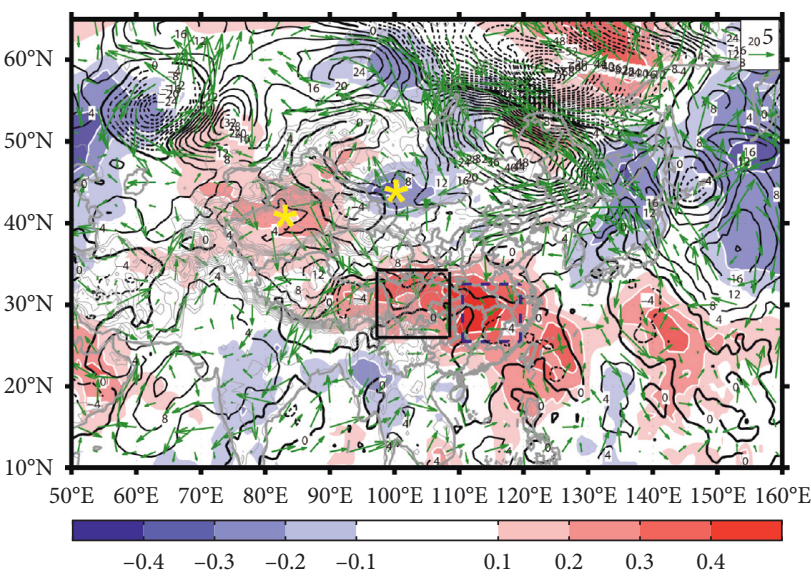

(g)

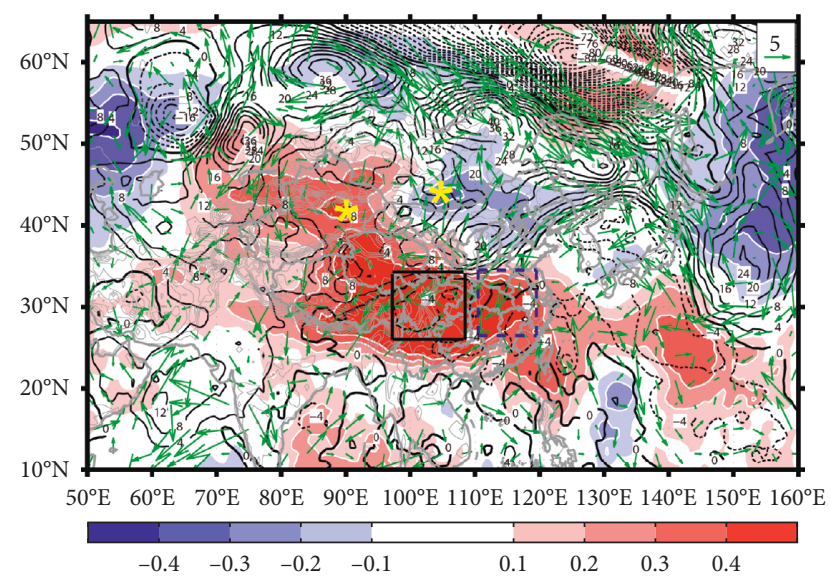

(h)

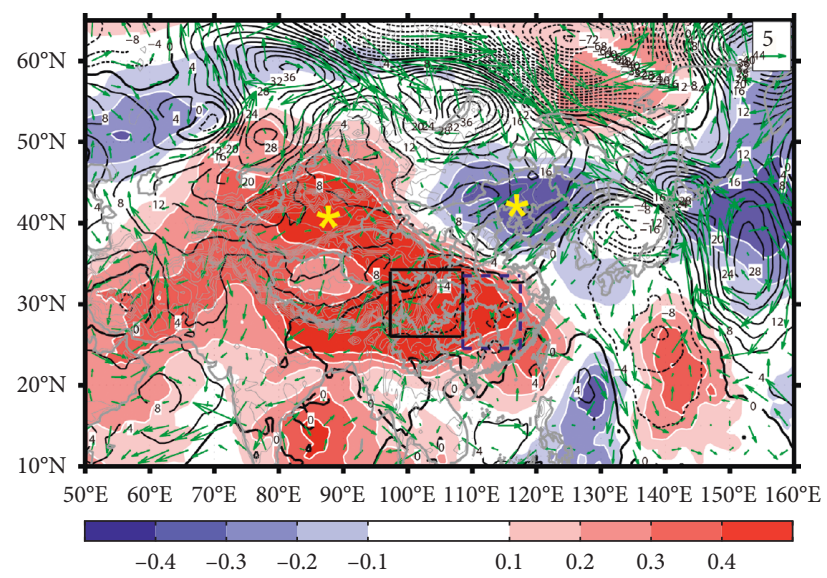

(i)

Figure 7: Correlation (color shading) between TPMVI and $500 \mathrm{hPa}$ GPH in the 50 -member forecast for next 0 to $84 \mathrm{~h}$ (12 h interval) is shown in (a-h) and for next 90-108 h (4-time average, 1800 UTC 17 July-1200 UTC 18 July) in (i) initialized at 0000 UTC 14 July 2013. The black contours and green vectors show the difference of $500 \mathrm{hPa} \mathrm{GPH} \mathrm{(contours;} \mathrm{unit:} \mathrm{gpm)} \mathrm{and} \mathrm{wind} \mathrm{(vectors;} \mathrm{unit:} \mathrm{m} / \mathrm{s}$ ) between six stronger and six weaker members (six stronger members minus six weaker members). The asterisk shows the significant location of the correlation according to the synoptic system's coherent rules. The blue boxes in Figures 7(a)-7(i) show the area with correlation coefficient roughly beyond the 95\% confidence level nearby WPSH, and the black boxes indicate the TPMV over the SCB, respectively.

confidence level. Figures $7(\mathrm{~h})-7(\mathrm{i})$ also illustrate that the negative value of the GPH over SCB is corresponding to the stronger TPMV in the subsequent time-averaged 90-108 $\mathrm{h}$ forecast of TPMV. The GPH in the forecast for next $48 \mathrm{~h}$ over the SCB can be viewed as a precursor of the subsequent timeaveraged $90-108 \mathrm{~h}$ forecast of TPMV in the east of TP.

4.3. Relationship between the TPMV and the Heavy Rainfall over the SCB. Similar instantaneous linear relationships are also evident between the averaged $500 \mathrm{hPa} \mathrm{GPH}$ and precipitation $(P)$ over the SCB (Figure 10). The correlation coefficient between the averaged $500 \mathrm{hPa}$ GPH and $P$ is -0.348 , which passed the $95 \%$ confidence level. This further demonstrates that TPMV may lead to more rainfall over the SCB. For example, higher (lower) heights usually correspond to less (more) precipitation. Since the averaged $500 \mathrm{hPa} \mathrm{GPH}$ can be regarded as an indication of the strength of the TPMV, the above results imply a positive correlation between the strength of TPMV and the total precipitation there.

\section{Concluding Remarks}

The heavy rainfall event was previously shown to be very difficult to be predicted at the medium term forecast [35]. The heavy rainfall was mainly influenced by the TPMV over the SCB. To investigate larger-scale factors influencing the development of the TPMV and associated heavy rainfall on 18 July 2013 over the SCB, statistical relationships were calculated to examine the atmospheric conditions influencing the development of the TPMV. The above results are summarized in Figure 11, which illustrates the weather situations in favor or not for the development of the TPMV and associated heavy rainfall.

TPMV, as a mesoscale baroclinic vortex, is influenced by the interaction of the cold and warm flows significantly [7]. 


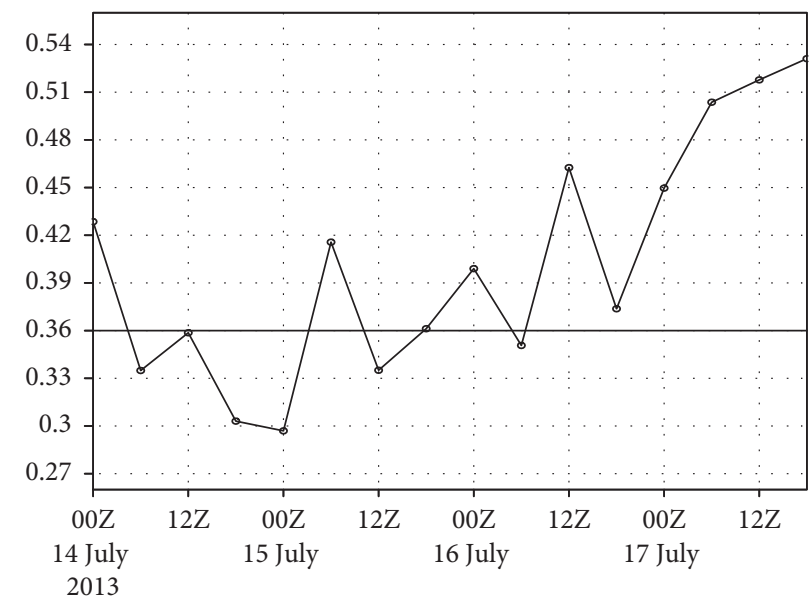

Figure 8: Time series (6 h interval) of correlations between WPSH (the averaged $500 \mathrm{hPa}$ GPH over the area in dashed blue box shown in Figure 6) in forecast for next 0-90 hours after the initial time and TPMVI. The horizontal line with $R=0.36$ shows the correlation reaching the $95 \%$ confidence level.

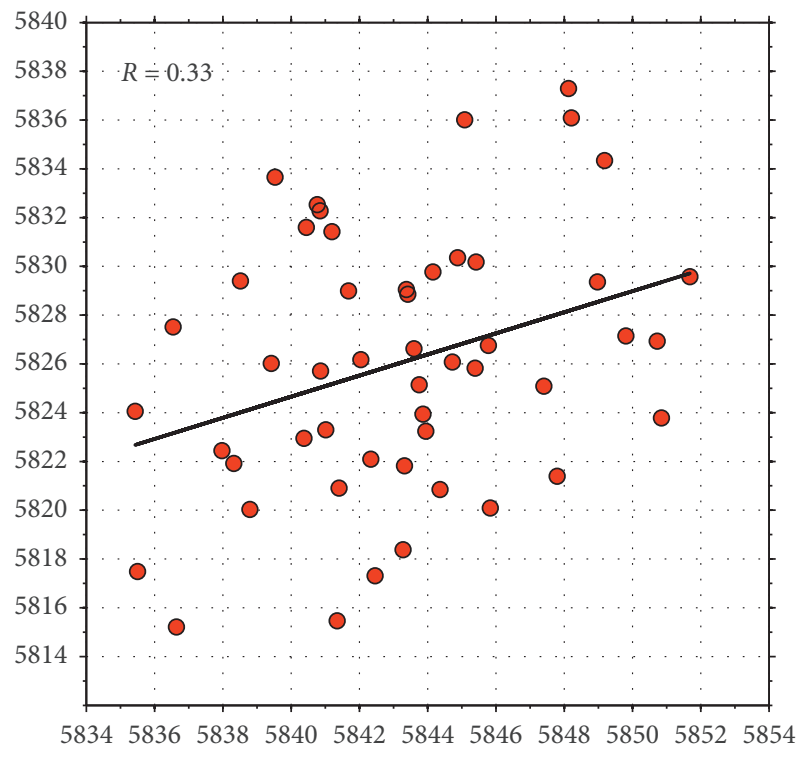

FIGURE 9: Scatter plot (red plots) of area-averaged $500 \mathrm{hPa} \mathrm{GPH}$ over SCB on 18 July (forecast for next 90-108 h, 4-time average, $y$ coordinate) vs averaged $500 \mathrm{hPa}$ GPH over SCB on 0000 UTC 16 July (forecast for next $48 \mathrm{~h}, x$-coordinate) in the 50 ensemble members after the initial time. The linear least squares fitting line is also shown. The linear correlation coefficient is given in the top left.

As shown in Figure 11, the TPMV is found to be closely related to the strength of two mid-high latitudes weather systems (e.g., Balkhash Lake ridge and Baikal Lake trough) and previous GPHs over the SCB and the WPSH area. Relatively weaker cold flow with a stronger ridge over the eastern of Balkhash Lake and a weaker trough over the southwest of Baikal Lake, meeting with the weaker warm flow coming from the WPSH, is favorable for the just location of TPMV over SCB. On the other hand, a relatively stronger cold flow coming from a weaker ridge over the eastern of Balkhash Lake and a stronger trough over the

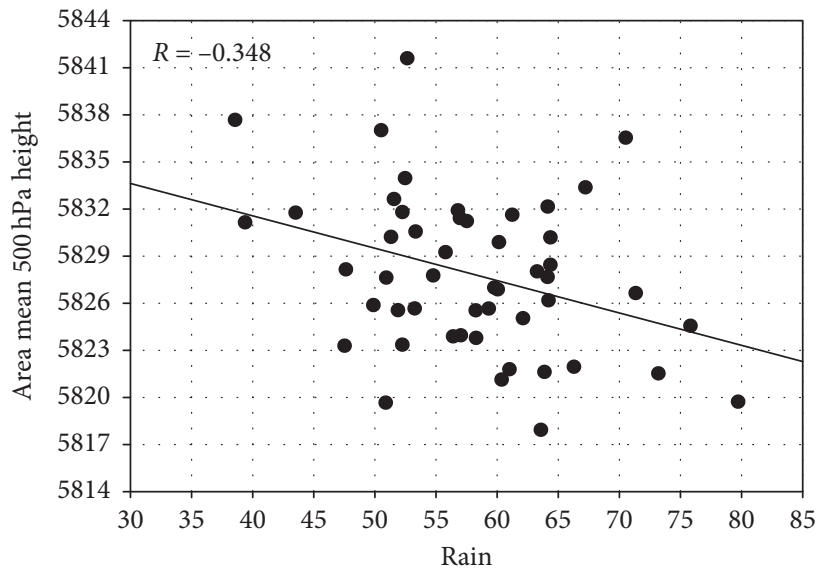

FIgURE 10: Scatter plot (black plots) of area-averaged $500 \mathrm{hPa}$ GPH over SCB ( $y$-coordinate) with precipitation over SCB $(x$ coordinate) in the 50 ensemble members on 18 July (forecast for next 90-108 h, 4-time average). The linear least squares fitting line is also shown. The linear correlation coefficient is given in the top left.

southwest of Baikal Lake, due to more cold flow into the western SCB as well as the resistance of stronger WPSH, results in the formation of TPMV over the west of SCB. The slightly further western location of the TPMV leads to less precipitation in the SCB. The GPHs in forecast for next $48 \mathrm{~h}$ over the SCB can be viewed as a precursor of subsequent time-averaged $90-108 \mathrm{~h}$ forecast of TPMV over the east of TP. These relatively small differences in the wind and weather situations early in the ensemble forecast, in conjunction with modifications of TPMV, will lead to very large spread in the resulting precipitation forecasts.

Compared with the deterministic forecast, by using correlation and composite methods, ensemble forecasts can demonstrate the mechanism of the TPMV formation more easily, thus helping to better understand the dynamics and predictability of the TPMV. For example, it is well known that cold air intrusion is an important forcing mechanism of 


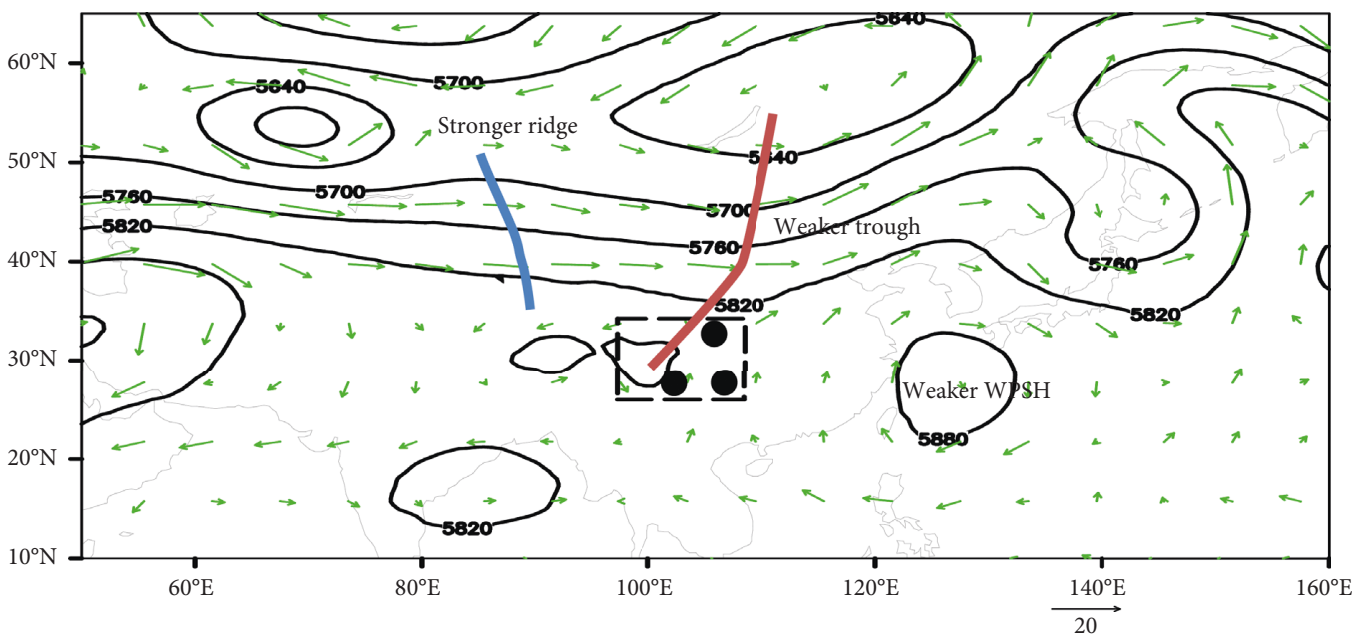

(a)

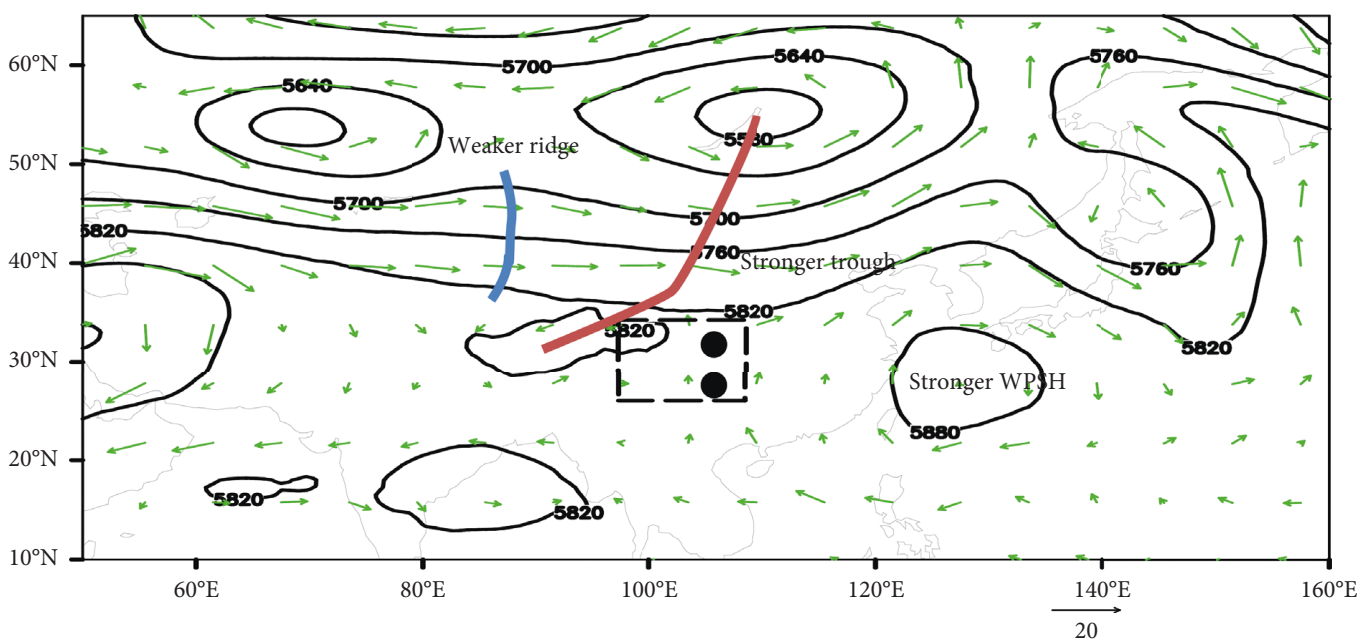

(b)

Figure 11: Schematic diagram illustrating the large-scale factors leading to (a) development (stronger members) and (b) nondevelopment (weaker members) of the TPMV and associated precipitation. Three black dots denote more rainfall while two black dots denote less rainfall.

the TPMV formation [3]. This case study shows that a weaker cold flow coming from the mid-high latitudes and a weaker WPSH are very important to the formation of the TPMV over the SCB. More TPMV cases can be studied using these methods to further verify the conclusion mentioned above, which will broaden the understanding of TPMV dynamic process and why this system can be predicted accurately.

\section{Data Availability}

The data used to support the findings of this study are available from the corresponding author upon request.

\section{Conflicts of Interest}

The authors declare that they have no conflicts of interest.

\section{Acknowledgments}

This work was jointly supported by the State Key Program of the National Natural Science of China (91337215 and 41475051), the Starting Foundation of the Civil Aviation University of China (2016QD05X), the Special Fund for Climate Change (CCSF201706), and the Special Fund for Development of Weather Forecasting Key Technologies (YBGJXM(2017)03-13).

\section{References}

[1] Y.-X. Gao, M.-C. Tang, S.-W. Luo, Z.-B. Shen, and C. Li, "Some aspects of recent research on the Qinghai-Xizang plateau meteorology," Bulletin of the American Meteorological Society, vol. 62, no. 1, pp. 31-35, 1981.

[2] S.-Y. Tao and Y.-H. Ding, "Observational evidence of the influence of the Qinghai-Xizang (Tibet) plateau on the occurrence of heavy rain and severe convective storms in 
China," Bulletin of the American Meteorological Society, vol. 62, no. 1, pp. 23-30, 1981.

[3] B. Wang, "The development mechanism for Tibetan plateau warm vortices," Journal of the Atmospheric Sciences, vol. 44, no. 20, pp. 2978-2994, 1987.

[4] P. Zhang, G. Li, X. Fu, Y. Liu, and L. Li, "Clustering of Tibetan plateau vortices by $10-30$ day intraseasonal oscillation," Monthly Weather Review, vol. 142, no. 1, pp. 290-300, 2014.

[5] S. W. Luo, Study of Several Synoptic Systems in the Tibetan Plateau and Adjacent Areas, China Meteorological Press, Beijing, China, 1992, in Chinese.

[6] H. Yamada and H. Uyeda, "Transition of the rainfall characteristics related to the moistening of the land surface over the central Tibetan plateau during the summer of 1998," Monthly Weather Review, vol. 134, no. 11, pp. 3230-3247, 2006.

[7] D. Z. Ye and Y. X. Gao, Meteorology of Tibetan Plateau, Science Press, Beijing, China, 1979, in Chinese.

[8] Z. S. Wang, Y. Wang, and Y. Liang, "A numerical simulation study of a heavy rain event induced by a southwest vortex," in Experimental, Synoptical and Dynamical Studies of Heavy Rain, pp. 257-267, China Meteorological Press, Beijing, China, 1996, in Chinese.

[9] X. Y. Shi, Y. Q. Wang, and X. D. Xu, "Effect of mesoscale topography over the Tibetan plateau on summer precipitation in China: a regional model study," Geophysical Research Letters, vol. 35, no. 19, p. 707, 2008.

[10] T. Yasunari and T. Miwa, "Convective cloud systems over the Tibetan plateau and their impact on meso-scale disturbances in the meiyu/baiu frontal zone," Journal of the Meteorological Society of Japan. Series II, vol. 84, no. 4, pp. 783-803, 2006.

[11] S. Yu, "Primary study on the impact of Tibetan plateau weather systems on the big flood peaks of the Yangtze river in 1998," in Mechanism and Prediction of 1998 Extreme Rainfall over the Yangtze River Basin and Nenjiang Valley, pp. 359-364, China Meteorological Press, Beijing, China, 2001.

[12] X. D. Xu and L. S. Chen, "Advances of the study on Tibetan plateau experiment of atmospheric sciences," Journal of Applied Meteorological Science, vol. 17, no. 6, pp. 754-772, 2006, in Chinese.

[13] S. Fu, W. Li, J. Sun, J. Zhang, and Y. Zhang, "Universal evolution mechanisms and energy conversion characteristics of long-lived mesoscale vortices over the Sichuan basin," Atmospheric Science Letters, vol. 16, no. 2, pp. 127-134, 2014.

[14] S. M. Fu, J. P. Zhang, J. H. Sun, and X. Y. Shen, "A fourteenyear climatology of the southwest vortex in summer," Atmospheric and Oceanic Science Letters, vol. 7, no. 6, pp. 510-514, 2014.

[15] H. Takahashi, "Formation of a rain belt and the structure of the front during the Baiu season on the Chinese continent," Geographical Review of Japan, Serries A, Chirigaku Hyoron, vol. 62 , no. 12 , pp. 853-876, 1989.

[16] L. Dell'Osso and S. J. Chen, "Numerical experiments on the genesis of vortices over the Qinghai-Tibet plateau," Tellus A-Dynamic Meteorology and Oceanography, vol. 38, no. 3, pp. 236-250, 1986.

[17] S. T. Gao, "The instability of the vortex sheet along the shear line," Advances in Atmospheric Sciences, vol. 17, no. 4, pp. 525-537, 2000.

[18] R. Shen, E. R. Reiter, and J. F. Bresch, "Some aspects of the effects of sensible heating on the development of summer weather systems over the Tibetan plateau," Journal of the Atmospheric Sciences, vol. 43, no. 20, pp. 2241-2260, 1986.
[19] S. Sugimoto and K. Ueno, "Formation of mesoscale convective systems over the eastern Tibetan plateau affected by plateau-scale heating contrasts," Journal of Geophysical Research, vol. 115, no. 16, 2010.

[20] K. Zhou, H. Liu, L. Zhao et al., "Binary mesovortex structure associated with southwest vortex," Atmospheric Science Letters, vol. 18, no. 6, pp. 246-252, 2017.

[21] X. Feng, C. Liu, R. Rasmussen, and G. Fan, "A 10-yr climatology of Tibetan plateau vortices with NCEP climate forecast system reanalysis," Journal of Applied Meteorology and Climatology, vol. 53, no. 1, pp. 34-46, 2014.

[22] X. Feng, C. Liu, G. Fan, X. Liu, and C. Feng, "Climatology and structures of southwest vortices in the NCEP climate forecast system reanalysis," Journal of Climate, vol. 29, no. 21, pp. 7675-7701, 2016.

[23] R. S. Schumacher, "Ensemble-based analysis of factors leading to the development of a multiday warm-season heavy rain event," Monthly Weather Review, vol. 139, no. 9, pp. 30163035, 2011.

[24] C. H. Qian, F. Q. Zhang, B. W. Green, J. Zhang, and X. Q. Zhou, "Probabilistic evaluation of the dynamics and prediction of supertyphoon Megi," Weather and Forecasting, vol. 28, no. 6, pp. 1562-1577, 2010.

[25] R. D. Tom, "Diagnosis of the downstream ridging associated with extratropical transition using short-term ensemble forecasts," Journal of the Atmospheric Sciences, vol. 67, no. 3, pp. 817-833, 2010.

[26] D. P. Hawblitzel, F. Zhang, Z. Meng, and C. A. Davis, "Probabilistic evaluation of the dynamics and predictability of the mesoscale convective vortex of 10-13 June 2003," Monthly Weather Review, vol. 135, no. 4, pp. 1544-1563, 2007.

[27] J. A. Sippel and F. Zhang, "A probabilistic analysis of the dynamics and predictability of tropical cyclogenesis," Journal of the Atmospheric Sciences, vol. 65, no. 11, pp. 3440-3459, 2008.

[28] J. A. Sippel and F. Zhang, "Factors affecting the predictability of hurricane Humberto (2007)," Journal of the Atmospheric Sciences, vol. 67, no. 6, pp. 1759-1778, 2010.

[29] J. Li, J. Du, D.-L. Zhang, C. Cui, and Y. Liao, "Ensemble-based analysis and sensitivity of mesoscale forecasts of a vortex over southwest China," Quarterly Journal of the Royal Meteorological Society, vol. 140, no. 680, pp. 766-782, 2014.

[30] Y. Wang, L. F. He, K. Dai et al., "An ensemble sensitivity analysis of a heavy rainfall over Sichuan Basin under interaction between plateau vortex and southwest vortex," Plateau Meteorology, vol. 36, no. 5, pp. 1245-1256, 2017, in Chinese.

[31] R. Buizza, J.-R. Bidlot, N. Wedi et al., "The new ECMWF VAREPS (variable resolution ensemble prediction system)," Quarterly Journal of the Royal Meteorological Society, vol. 133, no. 624, pp. 681-695, 2007.

[32] P. Bougeault, Z. Toth, C. Bishop et al., "The THORPEX interactive grand global ensemble," Bulletin of the American Meteorological Society, vol. 91, no. 8, pp. 1059-1072, 2010.

[33] D. P. Dee, S. M. Uppala, A. J. Simmons et al., "The ERAInterim reanalysis: configuration and performance of the data assimilation system," Quarterly Journal of the Royal Meteorological Society, vol. 137, no. 656, pp. 553-597, 2011.

[34] G. J. Hakim and R. D. Torn, "Ensemble synoptic analysis," Synoptic-Dynamic Meteorology and Weather Analysis and Forecasting, vol. 55, pp. 147-161, 2008.

[35] W. C. Liao, H. W. Liu, Y. X. Zhu, and N. Liang, "Analysis of heavy rainfall over Sichuan during 17-18 July 2013," 
Transactions of Atmospheric Sciences, vol. 39, no. 5, pp. 702-711, 2016, in Chinese.

[36] S. Y. TAO, Rainstorms in China, Science Press, Beijing, China, 1980, in Chinese.

[37] Y.-H. Kuo, L. Cheng, and R. A. Anthes, "Mesoscale analyses of the Sichuan flood catastrophe, 11-15 July 1981," Monthly Weather Review, vol. 114, no. 11, pp. 1984-2003, 1986.

[38] Chengdu Central Observatory, "A study of Sichuan extraordinary heavy rainfall in July 1981," in Collected Papers of Sichuan Basin Heavy Rainfall in 1981, pp. 12-37, Sichuan Meteorological Bureau, Chengdu, China, 1982. 

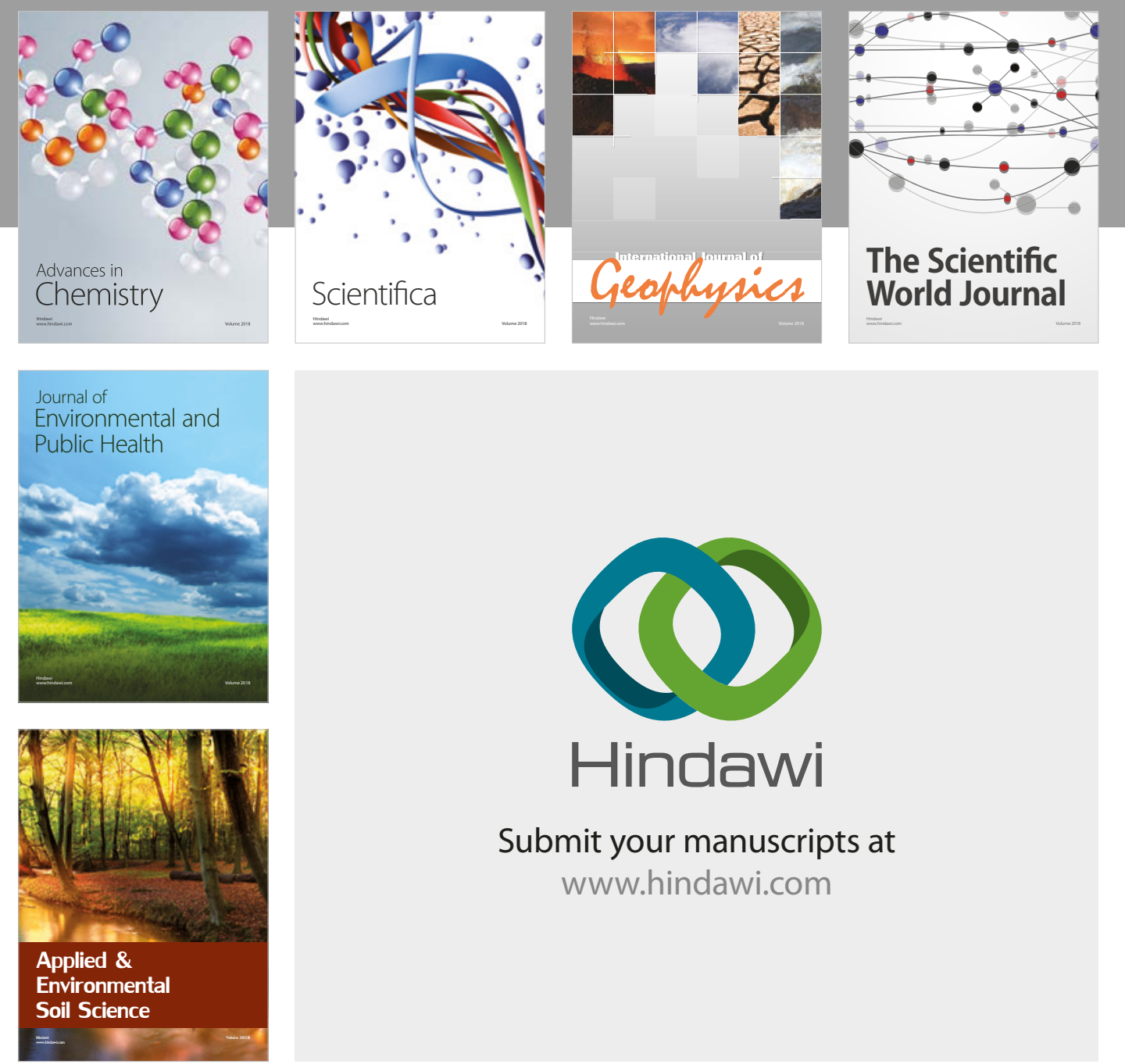

The Scientific

\section{World Journal}
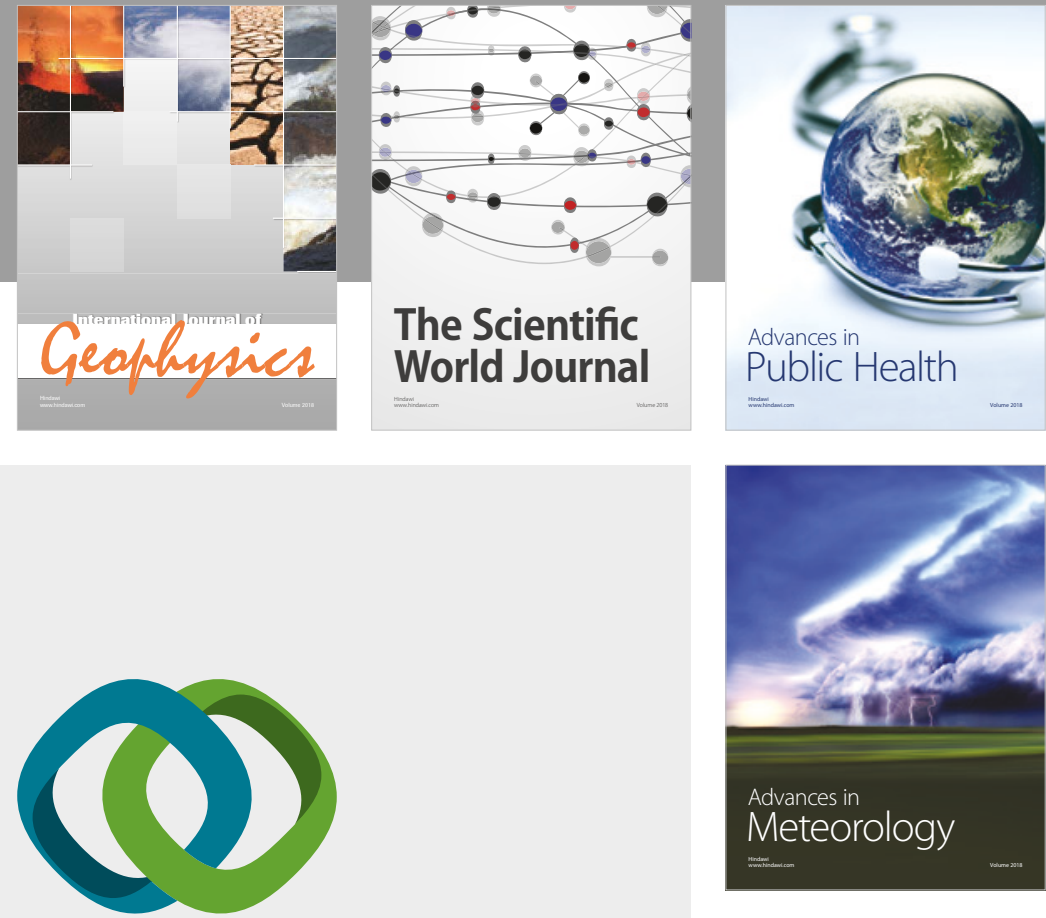

Advan

Public Health

\section{Hindawi}

Submit your manuscripts at

www.hindawi.com
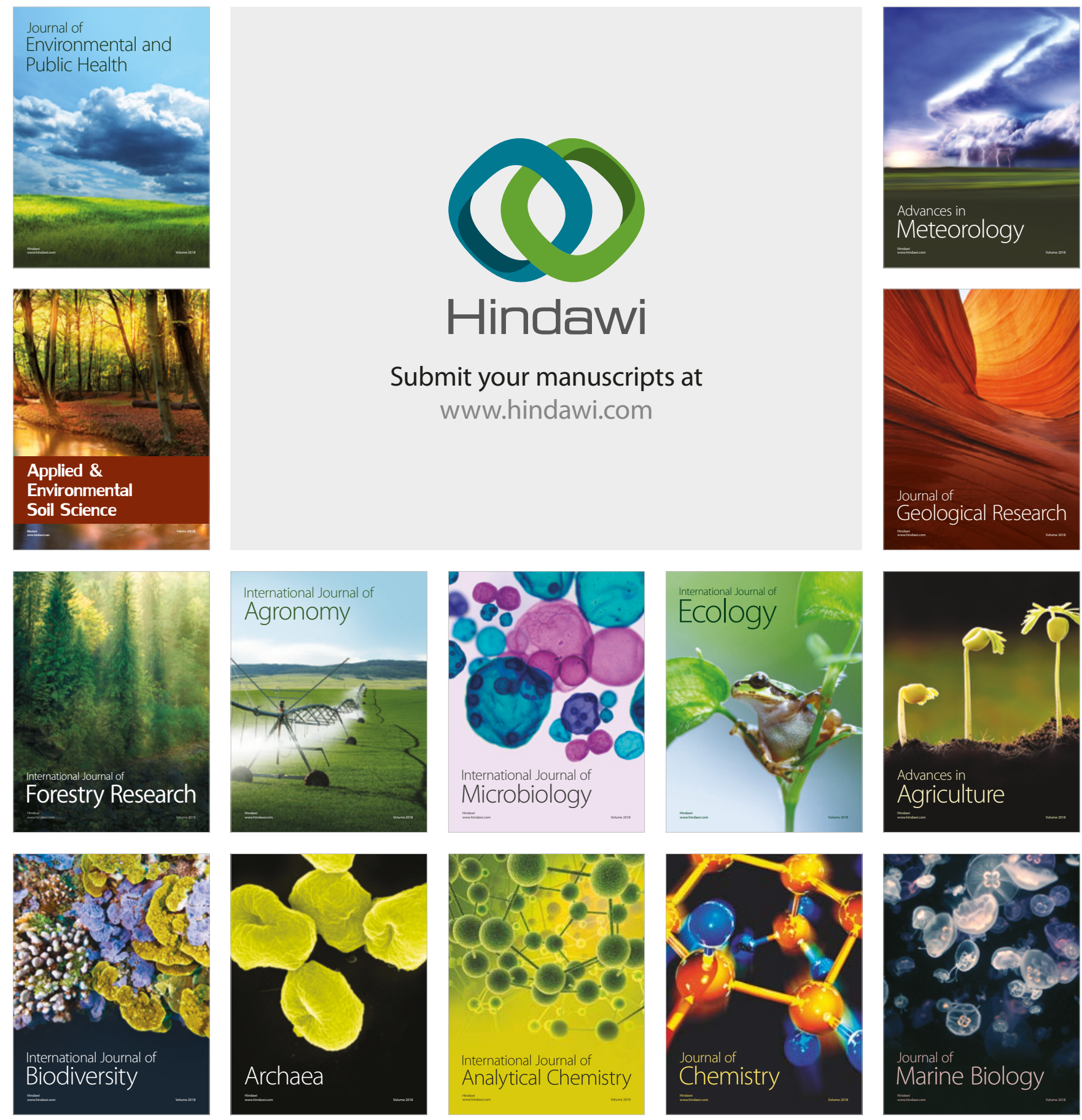